\title{
Uma visão pragmática de crenças de alunos sobre o ato de errar*
}

\section{A pragmatics view of learners' beliefs about erring}

Helena da Silva Guerra Vicente**

Fabíula Martins Ramalho***

Universidade Católica de Brasília - UCB

\begin{abstract}
RESUMO: Este trabalho tem por objetivo geral investigar se uma professora universitária e seus alunos partilham crenças a respeito da correção de composições escritas. Como objetivo específico, buscamos caracterizar as relaçôes entre duas crenças desse mesmo grupo de alunos: uma crença antiga de que errar é embaraçoso e deve ser evitado a todo custo, e uma crença em construção de que a correção individualizada de tarefas escritas pode ser benéfica, por permitir-lhes refletir mais demoradamente sobre os seus próprios erros. A primeira crença é inferida a partir de pistas linguísticas que denotam embaraço e distanciamento, presentes em certas estratégias de polidez negativa, como pedidos de desculpas e impessoalização. A segunda, por outro lado, não é facilmente inferida, mas pistas linguísticas conflitantes presentes na fala dos alunos podem ser o indicativo de uma mudança em curso. PALAVRAS-CHAVE: crenças; erro; correção individualizada; polidez negativa.
\end{abstract}

ABSTRACT: This study's main aim is to investigate whether a professor and her students share beliefs as far as the correction of written compositions is concerned. Our specific aim is to characterize the relationships operating among two beliefs of this group of students: an old belief that making errors is embarrassing and should be avoided at all costs, and a possibly newly-acquired belief that the oneto-one correction of written assignments can be advantageous, as it allows the students to reflect upon their own mistakes. The first belief is inferred through

\footnotetext{
* Agradecemos os comentários de dois pareceristas anônimos da Revista Brasileira de Linguística Aplicada e as valiosas contribuições do público presente no VIII ECEL (Encontro de Ciência Empírica em Letras), UFRJ, 2007, e no IV International Symposium on Politeness "East meets West", Hungarian Academy of Sciences, Budapeste, 2008. Agradecemos, finalmente, aos estudantes que participaram da pesquisa como nossos informantes.

** helenag@urb.br

*** fabiulamr@gmail.com
} 
linguistic cues which denote embarrassment and distancing, present in some negative politeness strategies, such as apologizing and impersonalization. The second belief, on the other hand, is not easily inferable, though conflicting linguistic cues in the students' speech might be signaling an ongoing change.

KEYWORDS: beliefs; error; one-to-one correction; negative politeness.

\section{Introdução}

Temos notado que os trabalhos sobre crenças, mais especificamente estudos de casos, têm-se pautado no pressuposto de que crenças têm de ser inferidas (cf. PAJARES, 1992), afirmação que julgamos correta. Entretanto, alguns desses mesmos trabalhos acabam por simplesmente relatar as respostas a questionários e entrevistas dos sujeitos de pesquisa (sejam estes alunos, professores em serviço ou em pré-serviço) como se aquelas correspondessem automaticamente às crenças desses indivíduos (cf. DUFVA, 2003, para uma opinião semelhante). Tendo em mente a necessidade de preencher esta que consideramos uma das maiores lacunas nos trabalhos sobre crenças, investigamos se um grupo de nove alunos de uma universidade particular de Brasília, todos cursando uma disciplina do curso de Letras denominada Expressão Escrita e Oral em Língua Inglesa, partilhava de algumas das crenças de sua professora, a saber: (i) a de que a correção oral individual de composições escritas pode ser bem-sucedida, pois permite aos alunos refletir/debruçar-se mais demoradamente sobre sua própria produção, e (ii) a de que é possível, e mesmo desejável, aprender a partir dos próprios erros, ${ }^{1}$ apontados e discutidos no momento da correção individualizada. A partir do uso abundante, por parte dos alunos, de estratégias de polidez negativa (BROWN; LEVINSON, 1987) - pedidos de desculpas e impessoalização - e de manutenção da face (GOFFMAN, 1959), refletidas em suas escolhas linguísticas, nós, estas pesquisadoras - respectivamente, a professora e a monitora da disciplina em questão -, fomos capazes de inferir a existência de uma crença mais antiga e profundamente enraizada em seu sistema de crenças de que cometer erros é vergonhoso, indesejável e deve, portanto, ser evitado a todo custo. Ao aliarmos as teorias de polidez e face à teoria de crenças, aceitamos a argumentação em Barcelos (2006) de que o uso de referenciais diversos pode trazer importantes revelações ao estudo de crenças.

"A palavra "erro" é utilizada aqui em sua acepção mais genérica. A distinção entre "erro" e "engano" não é relevante para a nossa análise. 
O artigo se encontra dividido da seguinte forma: na primeira seção, apresentamos quatro generalizações acerca do conceito de crença e introduzimos a distinção, crucial para este trabalho, entre crenças centrais e crenças periféricas (PAJARES, 1992). Na segunda seção, contextualizamos a pesquisa, que segue uma abordagem qualitativa. Em seguida, na terceira seção, discutimos as noções pragmáticas de polidez (BROWN; LEVINSON, 1987) e face (GOFFMAN, 1959), e como estas nos podem auxiliar no processo de inferência de crenças. Por fim, na quarta seção, discorremos sobre a possibilidade de haver discrepâncias entre o que os alunos dizem acreditar e o que realmente acreditam a respeito da correção individualizada. Para tanto, recorremos à noção de hotspots, ou "áreas de tensão", ${ }^{2}$ introduzida por Woods (1996).

\section{Crenças e crenças sobre aprendizagem de línguas}

O conceito de crenças remonta aos trabalhos de Charles S. Peirce (1877/ 1958) em filosofia (BARCELOS, 2004) e, antes de chegar à linguística, já havia sido abordado por outras disciplinas, como antropologia, sociologia, psicologia e educação. Cabe assinalar que a literatura sobre o tema mais específico "crenças sobre aprendizagem de línguas" tem-se desenvolvido de maneira mais evidente a partir de Horwitz (1985).

De acordo com Pajares (1992), é difícil chegar-se a uma definição una para o conceito de crença, mas é possível sistematizar os inúmeros trabalhos sobre o tema (dentre os autores citados, encontram-se ROKEACH, 1968; NISBETT; RON, 1980; NESPOR, 1987; SCHOMMER, 1990; WILSON, $1990)^{3}$ e encontrar pontos em comum entre estes. Dentre essas generalizações encontram-se, por exemplo, as seguintes: (i) crenças são cruciais no ato da definição de tarefas, (ii) as crenças de cada indivíduo afetam fortemente seu comportamento, (iii) crenças têm de ser inferidas, e (iv) quanto mais cedo uma crença é incorporada à estrutura de crenças, mais dificilmente será alterada; crenças recém-adquiridas são as mais vulneráveis a mudanças.

Interpretamos as duas primeiras assunções como tendo a ver diretamente com o comportamento mais facilmente observável da professora e seus alunos. A assunção (i) estaria relacionada ao fato de a professora ter escolhido a

\footnotetext{
2 Tradução sugerida em Barcelos (2006).

${ }^{3}$ Ver Pajares (1992, p. 324-326) para uma lista completa de autores e generalizações sobre crenças.
} 
correção individual com base em sua crença de que esse tipo de correção pode ser bem-sucedido e dá ao aluno a chance de refletir mais demoradamente sobre seu erro. De acordo com Almeida Filho (2007, p. 17), o que orienta as "decisões e ações do professor na construção do seu ensino (...) equivale a um conjunto de conhecimentos, crenças, pressupostos e eventualmente princípios sobre o que é (...) aprender e ensinar uma língua-alvo". A assunção (ii) estaria relacionada ao uso, por parte dos alunos, de estratégias de polidez negativa como a impessoalização e o pedido de desculpas, e isso refletiria a crença de que cometer erros é indesejável e embaraçoso. As noçóes de polidez e face serão abordadas mais adiante. As duas últimas assunçōes, por outro lado, estariam relacionadas a comportamentos menos observáveis na superfície e, por isso mesmo, mais difíceis de serem descritos e explicados. Argumentamos estarem justamente aí as maiores lacunas dos estudos sobre as crenças. Temos observado que os trabalhos em crenças sobre o ensino de línguas, mesmo demonstrando uma preocupação inicial com a assunção (iii), têm-se pautado nas respostas a questionários e entrevistas dos sujeitos de pesquisa como se estas correspondessem automaticamente às crenças desses indivíduos. Encontramos respaldo para essa nossa preocupação no trabalho de Dufva (2003), resumido em Barcelos (2006):

De acordo com Dufva (...), as afirmativas dos questionários não são crenças em si, mas apenas uma possível formulação das crenças. $\mathrm{O}$ problema metodológico de investigar crenças através dos questionários é que os dados não indicam o que as pessoas acreditam de fato, mas sim "como elas se relacionam com as afirmativas apresentadas a elas pelo pesquisador" (...) o paradigma de pesquisa que "reduz crenças a afirmativas de uma frase e depois interpreta as respostas de sim ou não como 'crenças' deve ser seriamente questionado" (BARCELOS, 2006, p. 21).

Goffman, em sua obra clássica, The Presentation of Self in Everyday Life (1959, p. 2), já afirmara que muitos fatos cruciais encontram-se escondidos em uma interação, e que as atitudes, crenças e emoções "verdadeiras" ou "reais" de um indivíduo somente podem ser verificadas indiretamente, por meio de confissões ou pela observação do que aparenta ser um "comportamento expressivo involuntário".

Interpretamos a assunção (iv) como estando relacionada ao que Pajares (1992, p. 318) chama de "emaranhado de crenças" ${ }^{4}$ (do original, belief

${ }^{4}$ Adotamos a tradução sugerida em Barcelos (2006, p. 35). 
network). Para esse autor, haveria, no sistema de crenças ${ }^{5}$ de um indivíduo, o que ele chama de "fios centrais ou periféricos desse emaranhado" - "fios" (do original, strands) aqui entendidos como as crenças propriamente ditas - que diferem entre si de acordo com a intensidade e as conexóes complexas que determinam sua importância. Assim, de acordo com as generalizações que faremos neste trabalho, interpretamos a proposta de Pajares da seguinte forma: uma crença mais antiga e enraizada (um "fio central") no sistema de crenças de um indivíduo teria maior grau de intensidade do que uma recém-adquirida (um "fio periférico"), sendo, portanto, mais difícil de ser alterada. Defendemos a idéia de que os dois tipos de crenças se influenciam mutuamente, em uma relação dialética, e o que buscamos provar por meio de nosso estudo de caso é que a intensidade de uma crença mais antiga é capaz de influenciar uma crença recém-adquirida, ou em fase de aquisição, ou ainda de barrar ou adiar o estabelecimento de uma crença que possa vir a ser adquirida. Inversamente, em se tratando de uma relação dialética, não se descarta a possibilidade de uma nova crença vir a se estabelecer, com maior ou menor grau de intensidade, no sistema de crenças de um indivíduo. Assim, buscaremos mostrar que a crença mais antiga de que cometer erros é embaraçoso e indesejável subjaz à crença potencialmente recém-adquirida de que a correção individual traz benefícios ao aluno, e que aquela é mais fácil de ser inferida do que esta última.

\section{A interação como um ritual: polidez e face}

A noção de "polidez" está fortemente ligada ao termo "face", ${ }^{6}$ difundido por Goffman (1959 e trabalhos subsequentes) a partir de uma expressão idiomática inglesa, to lose face ("sentir-se humilhado, envergonhado, constrangido" ou, mais informalmente, "quebrar a cara", "ficar com cara de tacho", "ficar com a cara no chão"). De acordo com esse autor, face é uma imagem que o indivíduo tem de si mesmo, delineada a partir de atributos socialmente aprovados. De acordo com Brown e Levinson (1987), há dois tipos de face: a "face negativa" e a "face positiva". É preciso esclarecer que as

\footnotetext{
${ }^{5}$ A noção de "sistema de crenças" foi amplamente desenvolvida em Linde (1980, apud WOODS, 1996).

${ }^{6}$ De acordo com Jim O'Driscoll (comunicação pessoal, 2008), apesar de os conceitos de polidez e face andarem sempre lado a lado, uma forma de entendê-los como duas noções dissociáveis é pensar que "face é algo que um indivíduo tem; polidez é algo que um indivíduo faz".
} 
palavras "positiva" e "negativa" não significam, dentro desse modelo, "boa" ou "ruim". Todo e qualquer indivíduo possui uma face negativa e uma face positiva, que correspondem, respectivamente, à necessidade de ser respeitado, e à necessidade de ser aceito e tratado como membro de um grupo (YULE, 1996).

Segundo Goffman, as interações sociais são conduzidas de duas maneiras - uma, defensiva, na qual o indivíduo tem o intuito de manter sua própria face, e a outra, protetora, em que procura manter a face do outro:

Algumas práticas são prioritariamente defensivas e, outras, protetoras, embora, em geral, possamos esperar que essas duas perspectivas estejam simultaneamente presentes em uma interação. Ao tentar preservar a face do outro, uma pessoa deve escolher uma linha de ação que não acarrete a perda da própria face; ao tentar preservar a própria face, ela deve levar em consideração a perda da face que sua ação pode acarretar para os outros (GOFFMAN, 1959, p. 9).

De acordo com Brown e Levinson (1987, p. 65), toda interação constituise de atos que, intrinsecamente, ameaçam a face, seja esta positiva ou negativa, seja esta a do falante ou a do ouvinte. Diz-se, portanto, que um ato ameaçador da face é aquele que vai contra as necessidades de face do falante ou do ouvinte. Os atos ameaçadores da face positiva são aqueles que indicam ausência, por parte do falante, de solidariedade ou de apreço pelos sentimentos do seu ouvinte. Incluem, por exemplo, acusações, insultos, comentários irreverentes e interrupção. Por outro lado, os atos ameaçadores da face negativa são aqueles que pressupõem uma ação futura por parte do ouvinte, como pedidos, sugestôes, conselhos, promessas e elogios, por exemplo. Os autores ressaltam, seguindo a mesma linha de raciocínio de Goffman, que, como toda interação se caracteriza como uma cooperação estabelecida entre falante e ouvinte, todo ato que ameaça a face do ouvinte vai, potencialmente, ameaçar a face do falante.

Notamos, de fato, que as estratégias de polidez negativa de que os alunos lançaram mão se prestavam tanto a manter a sua própria face quanto a da professora e a da monitora. Um exemplo extraído de uma das gravações das interações entre a professora e os alunos, e que pode ilustrar a argumentação de Goffman é:

(1) Ah, é que... foi... eu não consegui achar... eu até tava procurando assim no dicionário... é... "revezar".

(Tatiana ${ }^{7}$ - interação professora/aluno)

7 Todos os nomes são fictícios. 
Nesse exemplo, a informante, ao mesmo tempo em que preserva sua face se desculpando pelo fato de não ter encontrado a palavra "revezar" no dicionário ("eu não consegui achar"), sabe que está realizando um ato ameaçador da face da professora, mas, evitando a pergunta direta "Como se diz 'revezar'?", quer mostrar que está ciente disso - por meio de silêncios e hesitaçooes ("ah", "é que”, "até", "assim”, "é...") que denotam respeito, relutância e embaraço - e que está se esforçando para minimizar os efeitos da ameaça. Com isso, satisfaz as exigências da face negativa da professora, ao mesmo tempo em que mantém a sua própria.

Em suas interações diárias, espera-se que um indivíduo se comporte de maneira a ter sua imagem pública respeitada, e é por meio da polidez que ele mostra ter conhecimento da face do outro. Brown e Levinson (c.f. BROWN; LEVINSON, 1987, p. 101-129) apresentam uma lista de estratégias de polidez positiva, como "inclua o ouvinte na atividade", "pressuponha ou explicite reciprocidade", "faça piadas", entre outras (quinze ao todo). Em seguida, há uma lista de estratégias de polidez negativa (p. 129-211, dez ao todo); ${ }^{8}$ entre estas, encontram-se duas, a saber, "peça desculpas" e "impessoalize o falante e o ouvinte", cruciais para a nossa argumentação. A primeira, "peça desculpas", engloba duas sub-estratégias: o uso de comentários auto-depreciativos e o uso de justificativas. Os exemplos abaixo, extraídos de nossas gravaçōes, ilustram o uso dessas duas sub-estratégias:

(2) Peça desculpas: comentário auto-depreciativo

Ficou confuso até pra mim, agora.

(Leila - interação professora/aluna)

(3) Peça desculpas: justificativa

Eu acho que eu tenho medo mesmo assim é de falar errado inglês, entendeu? Acho que por isso que eu sou meio assim mais recatada.

(Ana Laura - interação monitora/aluna)

\footnotetext{
${ }^{8}$ É importante ressaltar, consoante Pan (2008), que as estratégias de polidez apresentadas no influente modelo de Brown e Levinson (1987) devem ser abordadas não isoladamente, mas em seus contextos específicos de uso: When approaching politeness in different languages [...], researchers are faced with the challenges that many linguistic features of politeness are either language-specific or situation-specific (tradução nossa: "Ao abordar a polidez em diferentes línguas [...], o pesquisador se defronta com o desafio de que muitos traços linguísticos de polidez são típicos de certas línguas ou situações específicas") (PAN, 2008, p. 4).
} 
No exemplo (2), após um pedido de esclarecimento da professora, a aluna se desculpa, por meio da elaboração de um comentário auto-depreciativo, dizendo que agora nem ela própria consegue entender o que havia escrito. Em (3), a desculpa aparece sob a forma de uma justificativa para o próprio erro; como tem medo de errar, ou, em outras palavras, como precisa proteger sua face negativa, a aluna prefere ser cautelosa e manter-se no que Colombo-Gomes chama de "zona de conforto" (2006). É interessante notar que, ao lançarem mão da estratégia "peça desculpas", os alunos em geral recorrem ao uso de pronomes de primeira pessoa ("eu", "mim"), o que parece denotar sua intenção de assumir a autoria do erro, eximindo a professora de qualquer tipo de responsabilidade.

A segunda estratégia, "impessoalize o falante e o ouvinte", utilizada com o objetivo de se evitar fazer referência manifesta ao sujeito da sentença, também foi amplamente encontrada nas gravaçóes:

(4) Impessoalize o falante

a. Quanto mais você refaz, mais erros ela vai encontrar, mais você vai aprender.

(Ana Carolina - interação monitora/aluna)

b. Ah, 'usually', é mesmo, professora, é vocabulário que falta na pessoa, e (...) [podendo ser também entendido como um pedido de desculpas] (Wagner - interação professora/aluno)

c. (...) individual a gente consegue pegar cada... o que mais a gente erra, né? O que a gente deve melhorar.

(Paulo - interação monitora/aluno)

d. Ninguém gosta de ser corrigido.

(Leila - interação monitora/aluna)

e. (...) acho que essa forma individual é bem melhor, até pra realmente o aluno adquirir um... realmente um conhecimento da matéria." (Luciana - interação monitora/aluna)

Ao contrário do que se observa no caso do pedido de desculpas, aqui, o falante procura distanciar-se da responsabilidade de ter cometido o erro, ao mesmo tempo em que mostra estar consciente de pertencer ao grupo denotado pela palavra ou expressão impessoal. Em (4a), observamos a substituição do pronome de $1^{\text {a }}$ pessoa, "eu", pelo de $3^{\text {a }}$, "você", usado de modo impessoal, mas, claramente inclusivo; em (4b), a impessoalização é marcada pelo uso da expressão "na pessoa", igualmente inclusiva. De (4c) a (4e), a impessoalização 
aparece sob a forma de "a gente", "ninguém" e "o aluno", respectivamente, todos incluindo, também, implicitamente, o falante.

\section{O contexto da pesquisa 0 grupo investigado}

Nosso estudo, desenvolvido no decorrer de um semestre letivo, teve como objeto de análise uma turma de nove alunos voluntários - calouros ou alunos de segundo ou terceiro semestre - seis do sexo feminino e três do sexo masculino, ' do curso de graduação em Letras de uma universidade em Brasília, cursando uma disciplina denominada Expressão Escrita e Oral em Língua Inglesa. A fim de terem sua identidade preservada, seus nomes foram substituídos por codinomes escolhidos pelas pesquisadoras.

Os dados obtidos são o resultado de duas baterias de gravações das interações entre professora e alunos no momento da correção individual de trabalhos escritos e duas baterias de entrevistas conduzidas pela monitora da disciplina, em que se procurou verificar se a professora da disciplina e seus alunos partilhavam crenças em relação a esse tipo de correção. As tarefas escritas, denominadas short compositions, foram designadas aos alunos em dois momentos do semestre. A primeira, logo no início do curso, teve como ponto de partida a resolução de exercícios de gramática e vocabulário, associados ao tema "divisão de tarefas domésticas entre homens e mulheres", trabalhado no livro North Star: focus on reading and writing (basic) de Natasha Haugnes e Beth Maher sob o título Scrub, Scour, and Smile!. Foram adotados os mesmos procedimentos em relação à segunda tarefa, designada na segunda metade do semestre, e o tema "encontrando o(a) parceiro(a) ideal" foi trabalhado na unidade denominada Finding a Spouse, do livro North Star: focus on reading and writing (intermediate), de Laurie Betta e Carolyn DuPaquier Sardinas. As unidades foram selecionadas de modo a suprir a deficiência do livro-texto adotado na disciplina (cujo título será mantido em sigilo) em relação à prática de escrita. As atividades - a resolução de exercícios de gramática e vocabulário, e a elaboração das composiçóes - foram realizadas em sala, ao longo de dois encontros para cada unidade, e aos alunos era permitida a consulta a dicionários,

\footnotetext{
9 Trata-se de uma informação puramente descritiva. Foge ao escopo deste trabalho uma análise aprofundada sobre o impacto do fator "gênero dos informantes" nos resultados da pesquisa.
} 
colegas e professora. Os exercícios relativos a cada uma das unidades foram corrigidos em sala, e, as composiçôes, entregues à professora para que ela pudesse corrigi-las em ambiente extra-classe. Nos encontros seguintes, sempre em um horário da aula designado para tal fim, a professora comentava as tarefas individualmente com cada um dos alunos, apontando erros e solicitando soluçóes. Cada uma das composiçóes poderia ser refeita e comentada quantas vezes o aluno desejasse, até o prazo estabelecido para a entrega da versão final. À monitora da disciplina coube a tarefa de realizar as entrevistas semi-estruturadas, pelo fato de a professora acreditar que os alunos ficariam mais à vontade na presença de uma outra aluna do curso. As questóes que serviram como ponto de partida para as conversas entre os alunos e a monitora foram as seguintes:

(5) Ponto de partida para as entrevistas semi-estruturadas

a. Como você se sente ao ser corrigido(a) (em qualquer tipo de situação, independentemente de serem tarefas escritas ou não)?

b. Por que motivo, você acha, a professora optou pela correção individualizada?

c. Para você, quais são as vantagens (se houver) e as desvantagens (se houver) da correção individualizada?

Nosso corpus constitui-se, portanto, das gravações das interações entre a professora e os alunos e das entrevistas semi-estruturadas realizadas pela monitora. Como veremos mais adiante, não é possível afirmar categoricamente se as crenças da professora, de que (i) é possível, e mesmo desejável, aprender a partir de nossos próprios erros e (ii) a correção individual, one-to-one, é mais eficaz, pois permite aos alunos refletir/debruçar-se mais demoradamente sobre sua própria produção, já se estabeleceram no sistema de crenças dos alunos. $\mathrm{O}$ que podemos afirmar com certeza é que, de um modo geral, os alunos sentemse constrangidos ao falar de seus erros. $O$ constrangimento fica evidente a partir do momento em que se nota o uso frequente de estratégias de polidez negativa, tais como justificativas para os próprios erros e comentários auto-depreciativos, enquadradas na classe maior dos pedidos de desculpas, bem como o uso da estratégia de impessoalização (BROWN; LEVINSON, 1987). A ocorrência dessas pistas linguísticas na fala dos alunos nos ajudou a inferir que uma crença mais antiga, subjacente à crença que nos propusemos verificar de início, é uma das razóes que leva os alunos a se sentirem constrangidos. Em outras palavras, a crença de que cometer erros é ruim, vergonhoso e deve ser evitado a todo custo está tão enraizada em seu sistema de crenças, que subjaz a uma crença recém-adquirida ou em fase de aquisição ou, ainda, na iminência de ser 
adquirida, de que o tipo de correção em questão poderia auxiliar o aperfeiçoamento da habilidade de escrita.

\section{Uma pesquisa de enfoque qualitativo}

O termo "metodologia qualitativa" se refere ao tipo de pesquisa que produz dados descritivos, específicos a uma determinada unidade, seja esta "uma escola, um professor, um aluno ou uma sala de aula" (ANDRÉ, 2007, p. 30-31). Além de indutiva, a pesquisa qualitativa é um processo criativo e intuitivo. Normalmente, ao realizar-se uma pesquisa de enfoque qualitativo, segue-se um plano bastante flexível, porque muitos questionamentos somente começam a tomar forma depois de o pesquisador ter passado certo tempo no ambiente que quer estudar, seja observando ou conversando com as pessoas em situaçôes reais do cotidiano (TAYLOR; BOGDAN, 1998). O objetivo inicial de nossa pesquisa, por exemplo, era verificar se uma professora de língua inglesa do curso de Letras de uma universidade particular em Brasília e seus alunos partilhavam crenças no que diz respeito à eficácia da correção individualizada de composiçóes escritas. No entanto, à medida que nosso estudo avançava, e, principalmente, após uma análise preliminar dos dados coletados, sentimos a necessidade de desenvolvê-lo à luz de noçóes da pragmática, tais como face (GOFFMAN, 1959 e trabalhos subsequentes), e polidez (BROWN; LEVINSON, 1987), por notarmos que os alunos, quando das interações com a professora e a monitora da disciplina, faziam escolhas linguísticas que denotavam desconforto, embaraço e insegurança em relação a seu próprio desempenho.

De acordo com Banister et alii (1997), ao se trabalhar com métodos qualitativos, deve-se aceitar o fato de que sempre haverá uma lacuna entre o objeto de estudo e a maneira pela qual é descrito. Essa lacuna, de acordo com Wolgar (1988, apud BANISTER et alii, 1997), pode aparecer sob três formas, denominadas "terrores metodológicos", a saber: (i) a indexicalidade, que leva uma descrição, válida para uma determinada ocasião, a modificar-se assim que o pesquisador se depare com uma situação nova; (ii) a inconclusibilidade, que dá a uma descrição a possibilidade de ser complementada, e, portanto, modificada continuamente, dependendo do quanto for adicionado a ela; e (iii) a reflexibilidade, relacionada ao fato de um mesmo fenômeno poder ser percebido de maneiras diferentes, por pesquisadores diferentes. A pesquisa qualitativa não tem como objetivo preencher a lacuna entre os objetos e suas representações de maneira definitiva. Por se tratar de uma abordagem 
interpretativa, busca-se trabalhar com o problema, e não contra ele. Ainda segundo Banister et alii (1997), quem opta por fazer pesquisa qualitativa deve trabalhar interpretativamente dentro dos terrores metodológicos, podendo até mesmo transformá-los em virtudes metodológicas.

Em relação à indexicalidade, Henwood e Pidgeon (1992) argumentam a favor da necessidade de se reformular uma descrição a partir do momento em que se esteja frente a uma nova situação. Espera-se, então, do pesquisador, uma teorização dessa mudança, na qual serão identificados os padróes de influência do contexto na pesquisa, e o modo pelo qual esses padrões são relevantes na obtenção dos resultados. Portanto, uma das características mais marcantes da pesquisa qualitativa não é a possibilidade de reaplicação de um trabalho, mas, sim, sua especificidade. Assim, as conclusões a que chegamos neste trabalho, específicas ao grupo investigado, podem servir como referência para outros trabalhos, mas não devem ser tomadas como verdades absolutas.

A inconclusibilidade, por sua vez, não deve ser encarada como um problema para o pesquisador, pois este deve entender que os resultados de uma pesquisa qualitativa serão sempre provisórios. Esse caráter provisório está diretamente associado à especificidade das descrições que compõem esse tipo de abordagem. Notamos, em relação ao grupo pesquisado, não ser possível afirmar categoricamente se a crença da professora em relação à correção individual de trabalhos escritos é partilhada com os alunos. Uma das conclusões interessantes a que chegamos é a de que, de um modo geral, uma crença recém-adquirida ou na iminência de ser adquirida não pode ser inferida facilmente (c.f. afirmaçōes conflitantes na seção Crenças estabelecidas e crenças em curso). Notamos, também que, no final das contas, nosso objetivo inicial foi sendo substituído pelo de se caracterizarem as relaçóes entre uma crença mais antiga e uma crença possivelmente recém-adquirida (cf. WOODS, 1996, p. 43, para uma experiência parecida).

De acordo com Banister et alii, a reflexibilidade diz respeito à oposição subjetividade/objetividade. Pesquisas de enfoque qualitativo consideram a subjetividade como um recurso valioso, e não como um problema. Haverá sempre de se considerar a "posição do pesquisador", e isso equivale a dizer que a tão almejada "neutralidade" deve ser totalmente descartada, já que, nesse tipo de abordagem, espera-se que o pesquisador, de alguma forma, exerça influência sobre o seu objeto de estudo. Nossa análise tem caráter essencialmente reflexivo, já que estas pesquisadoras correspondem à professora e à monitora em questão, e, enquanto a primeira reflete sobre sua própria prática, a outra tem a oportunidade de refletir sobre sua prática como monitora e futura professora. 


\section{Crenças estabelecidas e crenças em curso}

As crenças mais facilmente inferíveis, como vimos argumentando, são aquelas já bem estabelecidas, observáveis na superfície, por meio das escolhas linguísticas feitas pelo falante. Segundo vimos defendendo, a crença de que errar não é permitido foi possível de ser inferida a partir de marcas/pistas linguísticas, tais como o uso de palavra ou expressão impessoal, traduzido na estratégia "impessoalize o falante", e o uso muitas vezes exacerbado de hesitações e pronome de primeira pessoa do singular, traduzido na estratégia "peça desculpas". Conforme visto na seção anterior, ambas as estratégias denotam deferência, desconforto e consciência da face negativa tanto do ouvinte (no caso a professora) como do falante (o próprio aluno), e foram amplamente utilizadas nas interações com a professora e a monitora.

Por outro lado, o feedback obtido por meio das entrevistas semiestruturadas nos leva a crer que os alunos aprovam a técnica de correção empregada pela professora:

(6) Não existe desvantagem para uma correção individualizada.

(Wagner)

Nos excertos abaixo, por exemplo, os alunos verbalizam as duas crenças de que vimos tratando: a de que o tipo de correção em questão é eficiente, e a de que é possível aprender a partir dos próprios erros:

(7) (...) porque sempre que alguém chega até você e te corrige é porque tá te dando a oportunidade de melhorar.

(Tatiana)

(8) De fato o objetivo dela é fazer com que a gente se torne até mais críticos de nós mesmos, pra gente tentar entender que vão existir erros, que a aprendizagem, ela é um processo.

(Alexandre)

Os depoimentos a seguir reforçam as idéias expressas em (7) e (8), mas note-se já ser possível inferir, a partir do uso de palavras e expressões com conotação pejorativa, tais como "critica" e "chame a atenção" - em lugar de "corrige" -, a crença enraizada de que errar é embaraçoso:

(9) Se eu vejo que o professor realmente me critica pra que eu cresça, eu gosto, quando vejo que o professor critica pra me humilhar, aí já é diferente, aí eu já... então depende da situação.

(Luciana) 
(10) Quando a gente é corrigido, por mais que alguém chame a atenção da gente, a gente tá crescendo.

(Ana Laura)

Ainda assim, seria uma decisão apressada nos basearmos nas respostas às entrevistas para afirmarmos que as crenças de que (i) é possível, e mesmo desejável, aprender a partir de nossos próprios erros e (ii) a correção individual, one-to-one, é mais eficaz, pois permite aos alunos refletir/debruçar-se mais demoradamente sobre sua própria produção já foram de fato incorporadas ao sistema de crenças desses alunos. É difícil dizer, por exemplo, se um aluno que diz não haver desvantagem para uma correção individualizada (rever exemplo (6)) o faz apenas por acreditar que é o tipo de resposta que se espera de um aluno presumivelmente maduro de graduaçáo e que, pressupóe-se, tornar-seá professor daquela mesma disciplina no futuro. Da mesma maneira, não se pode afirmar que um aluno que tenha vergonha de ter seus erros apontados e comentados pela professora não acredite na eficácia de tal técnica. Será necessário mais tempo para que se investigue esse último aspecto a fundo; de um modo ainda bastante preliminar e intuitivo, arriscamos dizer que o aluno sente que o constrangimento é inevitável, porém está disposto a correr riscos e a vencer obstáculos, a fim de tornar-se proficiente na língua inglesa.

Muitos dos alunos que disseram aprovar a correção individualizada ou qualquer outro tipo de correção admitiram sentirem-se desconfortáveis nesse tipo de situação. As seguintes afirmações também foram extraídas das entrevistas:

(11) Eu acho que eu fico mais envergonhada de estar sozinha do que se ela me corrigisse na frente de todo mundo.

(Sandra)

(12) Quando você é corrigida na frente de todo mundo, você fica meio sem graça, constrangida de querer continuar a falar... o meu grande problema no inglês era justamente esse, que quando tava lá na sala todo mundo conversando inglês e se eu falasse alguma coisa errada e o professor me corrigisse, me travava, não conseguia mais falar.

(Ana Carolina)

(13) Poucas pessoas se sentem à vontade quando são chamadas a rever o que foi feito.

(Wagner) 
Em um trabalho sobre a cognição do professor, Woods (1996) notou a possibilidade de haver uma discrepância entre o que aquele diz acreditar e o que realmente faz em sala de aula. O autor refere-se a esses conflitos como hotspots, ou "áreas de tensão". Um dos casos apresentados por Woods, a fim de ilustrar esse raciocínio, é o de um professor que acreditava fortemente em uma determinada abordagem, mas que, ao mesmo tempo, acreditava na importância de agir de acordo com a expectativa e a motivação de seus alunos (c.f. WOODS, 1996, p. 208). Outro caso é o de uma professora que não conseguia evitar reagir com um "good", "that was very good", "that was excellent" às contribuiçôes de seus alunos, mas não estava contente com tal comportamento, por não gostar da idéia de colocá-los sob constante julgamento (c.f. WOODS, 1996, p. 214). Woods interpreta essa inconsistência entre as crenças de professores e seus comportamentos como o indicativo de áreas de tensão em sistemas de crenças em processo de evolução. ${ }^{10}$ Acreditamos poder estender a análise do autor à nossa própria, cujo foco são as crenças de alunos. Assim, com base no que foi coletado a partir das interaçōes e entrevistas, podemos argumentar que a discrepância entre os testemunhos apresentados acima ((6)(10) de um lado e (11)-(13) de outro) indicam, também, áreas de tensão em sistemas de crenças em evolução. Como a única certeza que temos, a partir da análise feita à luz das noções de polidez e face, é que, para os alunos, errar é embaraçoso, resta-nos concluir que os sistemas de crenças desses nove indivíduos sob investigação encontram-se em variados estágios de evolução.

Observamos, por exemplo, que os testemunhos em (14) mesclam o uso da estratégia de impessoalização ("a gente", "você", "seu”, "de cada um”...) ao uso do pronome de primeira pessoa "eu", fato que, ousamos dizer, é sintomático de uma mudança em curso:

(14)a. Eu gosto de ser corrigido, porque assim a gente aprende mais e ver o que a gente tá errando (...) quando o professor indica esses erros eu acho que é bom (...) isso me ajudou muito (...) eu escrevia a primeira versão, aí a gente dava pra ela e ela corrigia, depois apontava os erros e a gente tentava arrumar (...) melhora lá, depois corrigia, eu acho melhor (...) a gente tava escrevendo muito com a mentalidade em português. (Paulo)

\footnotetext{
${ }^{10}$ Ao referir-se ao que estamos chamando de "sistema de crenças", Woods utiliza a sigla BAK, que corresponde a beliefs, assumptions e knowledge. Foge ao escopo deste trabalho uma descrição mais detalhada desse modelo.
} 
b. Você tem que trabalhar o seu próprio erro (...) todo um processo, fazer, refazer, fazer de novo pra você se convencer (...) se você corrige aquele erro, o professor te acompanha, você tem aquela proximidade com seu texto (...) você tem uma relação mais afetiva até com ele (...) Nossa! Como ficou lindo! Eu nem achei que eu podia escrever desse jeito, às vezes você até começa até admirar o seu trabalho.

(Leila)

c. Gosto muito das aulas quando ela vai separadamente mostrar o erro de cada um, pra que com isso a gente possa aprender (...) (Ana Carolina)

Se não temos evidências suficientes para afirmar em que estágio se encontra o processo de incorporação da crença de que a correção individual pode trazer muitos benefícios ao aluno, temos, por outro lado, condiçōes de fazer generalizações sobre as relações que se estabelecem entre os diferentes tipos de crenças - centrais ou periféricas (nomenclatura em PAJARES (1992)). Para tanto, concentramo-nos nas relações entre a crença antiga de que errar não é permitido e a crença recém-adquirida ou em curso de que a correção oral individual de composições escritas pode ser bem-sucedida, por permitir aos alunos refletir/debruçar-se mais demoradamente sobre sua própria produção. Listamos abaixo essas generalizações:

(15) Relaçôes entre crenças: algumas generalizaçōes

(i) crenças centrais são mais facilmente inferíveis do que crenças periféricas;

(ii) o processo de inferência de crenças periféricas deve ter início após a inferência da crença central associada a elas;

(iii) a facilidade com que uma crença é inferida é inversamente proporcional à facilidade com que é alterada.

Cabe lembrar que a generalização (iii) foi feita com base em um pressuposto em Pajares (1992) de que quanto mais cedo uma crença é incorporada à estrutura de crenças, mais dificilmente será alterada. Desnecessário dizer, nossa generalização corrobora esse raciocínio do autor.

\section{Considerações finais}

Julgamos que a principal contribuição de nosso trabalho diz respeito à importância de se estabelecerem relações entre diferentes tipos de crenças, a 
saber, crenças antigas e crenças em aquisição ou recém-adquiridas de alunos. Com foco no tratamento do erro de trabalhos escritos, o estudo mostra que a identificação dessas relações é crucial para um entendimento do que o aluno pensa sobre o ato de errar, o ato de ser corrigido, e o modo pelo qual o conhecimento pode ser construído a partir dessas ações.

A partir de uma análise feita à luz das noções pragmáticas de "polidez" (BROWN e LEVINSON, 1987) e "face" (GOFFMAN, 1959 e trabalhos subsequentes), fomos capazes de identificar a existência de uma crença antiga e persistente de que o erro é algo que se deve evitar a todo custo. A palavra "vergonha", por exemplo, foi notada em várias das contribuições orais dos alunos, e as estratégias de polidez negativa "peça desculpas" e "impessoalize o falante" foram utilizadas em abundância.

Concluímos que a intensidade da crença de que errar é ruim nos dificulta inferir a crença de que o erro pode levar ao crescimento, e de que a correção individualizada pode ser bem-sucedida, pelo fato de permitir aos alunos refletir e debruçar-se mais demoradamente sobre sua própria produção. Não podemos afirmar se as contribuições em (6)-(10) refletem o pensamento real dos alunos, pois nada impede que sejam as crenças que eles, como pessoas supostamente maduras, gostariam de ter, e não as que têm realmente. No entanto, as pistas linguísticas conflitantes, expostas em (14) podem ser o primeiro vislumbre de uma mudança em curso. As conclusões a que chegamos corroboram o pressuposto em Pajares (1992) de que quanto mais cedo uma crença é incorporada ao sistema de crenças do indivíduo, mais difícil é alterá-la, e, consequentemente, o de que crenças recém-adquiridas são mais vulneráveis a mudanças. Além disso, a análise nos permitiu construir mais duas generalizações: a de que certos tipos de crença - centrais - são mais facilmente inferíveis do que outras - periféricas -, e a de que o processo de inferência de uma crença central deve ser anterior ao da crença periférica à qual está associada. Cabe ressaltar que a idéia de que diferentes tipos de crenças podem se influenciar mutuamente tem origem em Dewey (1910).

Neste trabalho, nos restringimos ao nível de identificação das relações de tensão existentes entre a crença central de que errar não é permitido e a crença periférica de que a correção individual pode ser benéfica. O estudo, no entanto, gera inúmeras questôes a serem investigadas, e uma delas seria a de se no discurso da professora/pesquisadora não haveria indícios de que ela própria enxerga o erro como algo que deve ser evitado. Seria interessante, também, investigar se homens e mulheres teriam crenças diferentes a respeito do tratamento do erro. Uma terceira questão, ainda, seria a de como preparar o aluno para o momento da correção individualizada. 


\section{Referências bibliográficas}

ALMEIDA FILHO, J. C. Dimensões comunicativas no ensino de línguas. Campinas: Pontes, 2007.

ANDRÉ, M. E. D. A. Etnografia da prática escolar. 13. ed. Campinas: Papirus, 2007.

BANISTER, E. W.; BURMAN, E.; PARKER, I.; TAYLOR, M.; TINDALL, C. Qualitative Methods in Psychology. London: Open University Press, 1997.

BARCELOS, A. M. Crenças sobre aprendizagem de línguas, Lingüística Aplicada e Ensino de Línguas. Linguagem \& Ensino, v. 7, n. 1, 2004, p. 123-156.

Cognição de professores e alunos: tendências recentes na pesquisa de crenças sobre ensino e aprendizagem de línguas. In: BARCELOS, A. M.; ABRAHÃO, M. H. (Org.). Crenças e ensino de linguas: foco no professor, no aluno e na formação de professores. Campinas: Pontes, 2006.

BROWN, P.; LEVINSON, S. Politeness: some universals in language usage. Cambridge: Cambridge University Press, 1987.

COLOMBO-GOMES, G. S. A promoção do êxodo da zona de conforto em uma sala de língua inglesa: a importância do papel da reflexão e da interação. Dissertação (Mestrado) - Pontifícia Universidade Católica de São Paulo, 2006.

DEWEY, J. How We Think. Lexington, Mass: D. C. Heath, 1910. Disponível em: <http://www.brocku.ca/MeadProject/Dewey/Dewey_1910a/Dewey_ 1910_a.html>. Acesso em: 15 jun. 2008.

DUFVA, H. Beliefs in Dialogue: a bakhtinian view. In: KALAJA, P.; BARCELOS, A. M. F. (Org.). Beliefs about SLA: New Research Approaches. Dordrecht: Kluwer, 2003. p. 131-151.

GOFFMAN E. The Presentation of Self in Everyday Life. New York: Anchor Books, 1959.

HENWOOD, K. L.; PIDGEON, N. F. Qualitative Research and Psychological Theorising. British Journal of Psychology, v. 83, n. 1, p. 97-111, 1992.

HORWITZ, E. K. Using Student Beliefs about Language Learning and Teaching in the Foreign Language Methods Course. Foreign Language Annals, v. 18, n. 4, p. 333-340, 1985.

NESPOR, J. The Role of Beliefs in the Practice of Teaching. Journal of Curriculum Studies, v. 19, n. 4, p. 317-328, 1987.

NISBETT, R.; ROSS, L. Human Inference: strategies and shortcomings of social judgment. Englewood Cliffs, NJ: Prentice-Hall, 1980. 
PAJARES, M. F. Teachers' Beliefs and Educational Research: Cleaning Up a Messy Construct. Review of Educational Research, v. 62, n. 3, p. 307-332, 1992.

PAN, Y. Looking Beyond the Form of Linguistic Presentation: approach to politeness across cultures. In: INTERNATIONAL SYMPOSIUM ON POLITENESS "EAST MEETS WEST", 4. 2-4 de julho de 2008, Budapeste, Hungria. Anais...

ROKEACH, M. Beliefs, Attitudes, and Values: a theory of organization and change. San Francisco: Jossey-Bass, 1968.

SCHOMMER, M. Effects of Beliefs About the Nature of Knowledge on Comprehension. Journal of Educational Psychology, 82, p. 498-504, 1990.

TAYLOR, S.; BOGDAN, R. Introduction to Qualitative Research Methods: a guidebook and resource. New York: John Wiley \& Sons, 1998.

WILSON, S. M. The Secret Garden of Teacher Education. Phi Delta Kappa, 72, p. 204-209, 1990.

WOODS, D. Teacher Cognition in Language Teaching: beliefs, decision-making, and classroom practice. Cambridge: Cambridge University Press, 1996.

YULE, G. Pragmatics. Oxford: Oxford University Press, 1996.

Recebido em julho de 2008. Aprovado em Agosto de 2008. 